\title{
An adaptive variant of TRIB2, rs1057001, is associated with higher expression levels of thermogenic genes in human subcutaneous and visceral adipose tissues
}

\author{
Kazuhiro Nakayama* and Sadahiko Iwamoto
}

\begin{abstract}
Background: An obesity-related single-nucleotide polymorphism (SNP) of the Tribbles pseudokinase 2 gene (TRIB2) was shown to have underwent adaptive evolution in the last glacial period, suggesting a selective advantage of this SNP in human populations in cold environments. In order to verify this hypothesis, the effect of the TRIB2 SNP on the expression of genes involved in adaptive thermogenesis was tested using messenger RNAs prepared from adipose tissues of Japanese adults.
\end{abstract}

Methods: Complementary DNA was prepared from subcutaneous adipose tissues (SAT) and visceral adipose tissues (VAT) obtained from 48 Japanese adults. Transcript levels of 15 selected genes, including five genes that are upregulated in development of thermogenic adipocytes, were measured by using real-time polymerase chain reaction. Differences in transcript levels between the TRIB2 SNP genotype groups (AA genotype versus AT $+\pi$ genotype) were assessed using $t$ test.

Results: Of the five thermogenic genes, DIO2, CIDEA, PPARGC1A, and PRDM16 showed significantly higher transcript levels in SAT of individuals with the AA genotype relative to those with the AT + Tा genotype $(P<0.05)$. However, only 2 out of the 10 non-thermogenic genes exhibited differences in transcript levels according to genotype. Additionally, in silico prediction indicated that this SNP likely affects the expression of nearby genes including TRIB2.

Conclusion: The higher expression levels of thermogenic genes in individuals homozygous for the adaptive variant of TRIB2 SNP suggest a greater propensity for induction of thermogenesis in adipose tissues in cold environments.

Keywords: TRIB2, SNP, Thermogenesis, Obesity

\section{Background}

The primary cause of obesity is an imbalance between caloric intake and energy expenditure. Susceptibility to obesity in present human populations is thought to be shaped by past genetic adaptation to famine [1, 2]. Additionally, lower ambient temperatures may exert selective pressure on genetic variations that influence susceptibility to obesity, as cold-induced thermogenesis substantially increases energy expenditure [3]. It may be hypothesized that genotypes linked to higher thermogenic capacity and leaner phenotypes were adaptive in

\footnotetext{
* Correspondence: nakayama@jichi.ac.jp

Division of Human Genetics, Center for Molecular Medicine, Jichi Medical University, 3311-1 Yakushiji, Shimotsuke 329-0498, Japan
}

archaic human populations during glacial periods [4]. A single-nucleotide polymorphism (SNP) in the uncoupling protein 1 gene, an essential gene for thermogenesis in brown adipocytes, has been shown to support the role of adaptation to cold climates in shaping the susceptibility to obesity $[5,6]$.

A previous study reported that a functional SNP in the 3 ' untranslated region of the tribbles pseudokinase 2 gene (TRIB2) strongly influences visceral fat accumulation in Japanese adults. The obesity-resistance-associated allele of TRIB2 underwent positive natural selection in East Asians during the last glacial maximum, suggesting that this TRIB2 variant links past adaptation to present resistance to obesity [7]. TRIB2 suppresses the 
differentiation of adipocytes by promoting the degradation of the CCAAT/enhancer binding protein beta (CEBPB), a transcription factor that acts during early stages of brown adipocyte development [8, 9]. Human brown adipocytes are thought to be present only during early life in humans; however, recent studies have indicated the existence of active brown adipocytes in adult humans [10]. Moreover, it has been shown that energy-storing white adipocytes (or/ and their progenitor cells) may be transformed into thermogenic beige/brite adipocytes via a series of stimuli; these thermogenic adipocytes resemble brown adipocytes but possess distinctive developmental lineages [11]. The adaptive TRIB2 allele, which is associated with the reduction of visceral fat, may contribute to resistance to cold environments by increasing the activity of these thermogenic adipocytes. In the present study, we examined the effects of the previously reported TRIB2 SNP on the expression of genes involved in thermogenesis in the adipose tissues of Japanese adults.

\section{Methods}

Subcutaneous adipose tissue (SAT) and visceral adipose tissue (VAT) samples were obtained from 48 Japanese adults. These participants were enrolled from among patients admitted to the Jichi Medical University Hospital for gastrointestinal surgery or gynecological surgery. All participants provided written informed consent. SAT was collected from the abdominal skin incision and VAT from the extirpated organ, omentum, or mesenterium during surgical procedures. Complementary DNA (cDNA) and genomic DNA were prepared from adipose tissue specimens. Details of participants and samples were described in the previous paper [12]. The TRIB2 SNP (dbSNP: rs1057001) was genotyped using TaqMan Genotyping Assays and ABI PRISM 7900HT [7]. Transcription levels of selected genes were measured using TaqMan Gene Expression Assays or RT-PCR with SYBR Green on an ABI PRISM 7900HT. The list of target genes is shown in Table 1. Transcript levels of the target genes were normalized to that of the actin beta gene (measured by the TaqMan method) using the delta $\mathrm{Ct}$ method. Statistical tests were performed using SPSS version 23. Epigenetic modification patterns near rs1057001 and tightly linked variants $\left(r^{2}>0.8\right.$ in the 1000 Genome Project East Asians) were retrieved using Haploreg4.1 [13]. The design of the present study was approved by the ethical committee of Jichi Medical University.

Table 1 Tested genes

\begin{tabular}{|c|c|c|c|}
\hline Symbol & Gene name & Function & $\begin{array}{l}\text { Assay type and nucleotide sequences } \\
\text { of primers }{ }^{a}\end{array}$ \\
\hline CIDEA & Cell death-inducing DFFA-like effector A & Development of brown/beige adipocytes & $\begin{array}{l}\text { 5'-CAGCTCGCCCTTCCGGGTC } \\
\text { 5'-CGAGGGCATCCAGAGTCTTGCT }\end{array}$ \\
\hline $\mathrm{D} / \mathrm{O} 2$ & lodothyronine deiodinase 2 & Thermogenesis & $\begin{array}{l}\text { 5'-AGAGGGACTGCGCTGCGTCT } \\
\text { 5'-TGCACCACACTGGAATTGGGGG }\end{array}$ \\
\hline PDRM16 & PR/SET domain 16 & Development of brown/beige adipocytes & $\begin{array}{l}\text { 5'-GAACCAGGCATATGCAATGATGCTG } \\
\text { 5'-CCAGCCCGTCAGAGGTGGTTG }\end{array}$ \\
\hline PPARGC1A & PPARG coactivator 1 alpha & Development of brown/beige adipocytes & $\begin{array}{l}\text { 5'-AGACACCGCACGCACCGAAAT } \\
\text { 5'-AGCTGTCATACCTGGGCCGACG }\end{array}$ \\
\hline UCP1 & Uncoupling protein 1 & Thermogenesis & $\begin{array}{l}\text { 5'-CGGCCTCTACGACACGGTCCA } \\
\text { 5'-ACGACCTCTGTGGGTTGCCCAA }\end{array}$ \\
\hline$A C C$ & Acetyl-CoA carboxylase & Fatty acid synthesis & TaqMan \\
\hline DGAT1 & Diacylglycerol O-acyltransferase 1 & Triglyceride synthesis & $\begin{array}{l}\text { 5'-GCCCCCAACAAGGACGGAGAC } \\
\text { 5'-CCACACACCAGTTCAGGATGCCA }\end{array}$ \\
\hline FASN & Fatty acid synthase & Fatty acid synthesis & TaqMan \\
\hline SCD1 & Stearoyl-CoA desaturase 1 & Fatty acid synthesis & TaqMan \\
\hline SREBP1 & Sterol regulatory element-binding protein 1 & Master regulator of fatty acid synthesis & TaqMan \\
\hline ADIPOQ & Adiponectin & Adipocytokine & TaqMan \\
\hline FABP4 & Fatty acid-binding protein 4 & Incorporation of fatty acids & $\begin{array}{l}\text { 5'-TGGGGGTGTCCTGGTACATGTGC } \\
\text { 5'-ACGCCITTCATGACGCATTCCACC }\end{array}$ \\
\hline$A D R B 3$ & Adrenoceptor beta 3 & Lipolysis & TaqMan \\
\hline GLUT4 & Facilitated glucose transporter, member 4 & Incorporation of glucose & $\begin{array}{l}\text { 5'-TTGGCCCTGGCCCCATTCCT } \\
\text { 5'-GCCCCATAGCCTCCGCAACA }\end{array}$ \\
\hline$L E P$ & Leptin & Adipocytokine & $\begin{array}{l}\text { 5'-TAGGAATCGCAGCGCCAGCGG } \\
\text { 5'-ATCCGCACAGGGTTCCCCAATG }\end{array}$ \\
\hline
\end{tabular}




\section{Results and discussion}

The genotypes of rs1057001 in participants were AA $=26$, $\mathrm{AT}=20$, and $\mathrm{TT}=2$. The proportion of the three genotypes was in Hardy-Weinberg equilibrium status $(P=$ 0.421 , chi square test, degrees of freedom $=1$ ). Individuals with TT genotype were infrequent and thus combined with individuals with AT genotype for further statistical analyses. Genotype groups did not show differences in terms of the proportion of males and females $(P=0.066$, Fisher's exact test), age ( $P=0.253, t$ test), and body mass index $(P=0.960, t$ test $)$.

The transcript levels of tested genes are shown in Table 2. We tested CIDEA, DIO2, PPARGC1A, PRDM16, and $U C P 1$, which were previously linked to brown adipose tissue activity as well as induction of beige/brite adipocytes in mice and humans [14-18]. The UCP1 transcript was undetectable in the majority of the adipose tissue samples. Transcripts of the other four genes were present at higher levels in individuals with the AA genotype than in those with the AT + TT genotype $(P<$ $0.05, t$ test). The level of PPARGC1A expression in SAT was significant, at $5 \%$ after the Bonferroni correction (numbers of successfully measured gene $=14$ ). The genotypic differences in the transcript levels of thermogenic genes were more notable in SAT, in which induction of beige/brite adipocytes was observed in mice and humans [11]. Furthermore, CIDEA and PRDM16 showed higher expression levels in SAT than in VAT ( $P$ $<0.05$, after the Bonferroni correction was applied), supporting the greater prepotency of SAT for thermogenesis. We additionally tested the effect of TRIB2 genotypes on the expression of genes for de novo lipogenesis in white adipocytes (ACC, DGAT1, FASN, SCD1, $S R E B P 1)$ and genes commonly expressed in white and brown adipocytes (ADIPOQ, ADRB3, FABP4, GLUT4, and $L E P$ ). Of the 10 genes, only ADIPOQ and GLUT4 in SAT showed significant differences in expression between the genotype groups $(P<0.05, t$ test).

The previous study showed that the A allele of rs1057001 is linked to lower transcription levels of TRIB2 in adipose tissues [7]. We additionally investigated epigenetic modifications of rs1057001 and short nucleotide sequence variants with tight linkage disequilibrium status with rs1057001 (Fig. 1). Several of these variants were found in genome sequences with signatures of gene regulatory elements, including histone enhancer marks, DNase hypersensitive sites, and alteration of protein-binding motifs. These variants are considered to coordinately alter expression levels of TRIB2 in various tissues. The transcription level of a microRNAencoding gene (MIR3125) as well as of TRIB2 showed significant correlations with genotypes of rs1057001 or the tightly linked variants. Although the physiological function of MIR3125 is still unknown, this gene is thought to contribute to the genotype-related effects of the TRIB2 variant of the thermogenic genes.

Higher expression levels of genes involved in the differentiation and function of brown and beige/brite adipocytes may indicate a greater propensity for thermogenesis in individuals with the AA genotype in response to cold stimuli. This observation may support the hypothesis that the A allele contributed to cold

Table 2 Transcription levels of the tested genes in the TRIB2 genotype groups

\begin{tabular}{|c|c|c|c|c|c|c|c|c|}
\hline \multirow[t]{2}{*}{ Gene symbol } & \multicolumn{2}{|c|}{$\begin{array}{l}\text { Mean (SD) transcription level in subcutaneous } \\
\text { adipose tissues }\end{array}$} & \multirow[t]{2}{*}{ Ratio } & \multirow[t]{2}{*}{$P$} & \multicolumn{2}{|c|}{$\begin{array}{l}\text { Mean (SD) transcription level in visceral } \\
\text { adipose tissues }\end{array}$} & \multirow[t]{2}{*}{ Ratio } & \multirow[t]{2}{*}{$P$} \\
\hline & $\overline{\mathrm{AA}}$ & $\mathrm{AT}+\mathrm{TT}$ & & & $\overline{\mathrm{AA}}$ & $\mathrm{AT}+\mathrm{TT}$ & & \\
\hline CIDEA & $0.4474(0.1986)$ & $0.2999(0.2094)$ & 1.45 & 0.016 & $0.2962(0.2511)$ & $0.1897(0.1572)$ & 1.55 & 0.095 \\
\hline $\mathrm{D} / \mathrm{O} 2$ & $0.0012(0.0017)$ & $0.0005(0.0003)$ & 2.51 & 0.036 & $0.0012(0.0009)$ & $0.0006(0.0007)$ & 2.00 & 0.015 \\
\hline PPARGCIA & $0.0023(0.0015)$ & $0.0012(0.0005)$ & 1.80 & 0.002 & $0.0017(0.0009)$ & $0.0012(0.0009)$ & 1.51 & 0.034 \\
\hline PRDM16 & $0.0074(0.0058)$ & $0.0041(0.0033)$ & 1.73 & 0.021 & $0.0028(0.0022)$ & $0.0018(0.0014)$ & 1.58 & 0.084 \\
\hline$A C C$ & $0.0054(0.0038)$ & $0.0082(0.0061)$ & 0.65 & 0.065 & $0.0045(0.003)$ & $0.006(0.0034)$ & 0.75 & 0.112 \\
\hline DGAT1 & $0.0405(0.024)$ & $0.044(0.0227)$ & 0.96 & 0.61 & $0.0935(0.0371)$ & $0.1052(0.0652)$ & 0.88 & 0.440 \\
\hline FASN & $0.2635(0.1727)$ & $0.4259(0.3704)$ & 0.60 & 0.069 & $0.2006(0.1452)$ & $0.2739(0.2178)$ & 0.72 & 0.172 \\
\hline SCD1 & $0.8676(0.8784)$ & $1.3172(1.7992)$ & 0.64 & 0.266 & $0.7727(0.7134)$ & $0.8298(1.0251)$ & 0.72 & 0.822 \\
\hline SREBP1 & $0.0238(0.0126)$ & $0.0366(0.0268)$ & 0.64 & 0.050 & $0.0255(0.0345)$ & $0.0213(0.0138)$ & 1.19 & 0.577 \\
\hline ADIPOQ & $0.5757(0.2606)$ & $0.8252(0.4946)$ & 0.69 & 0.041 & $0.4176(0.3337)$ & $0.4953(0.2959)$ & 0.85 & 0.402 \\
\hline ADRB3 & $0.002(0.0021)$ & $0.0017(0.0023)$ & 1.13 & 0.667 & $0.0017(0.0018)$ & $0.0021(0.0027)$ & 0.80 & 0.590 \\
\hline FABP4 & $1.683(0.84)$ & $1.2587(0.6681)$ & 1.31 & 0.068 & $0.7458(0.4979)$ & $0.718(0.4251)$ & 1.09 & 0.839 \\
\hline GLUT4 & $0.0463(0.0462)$ & $0.0241(0.0192)$ & 1.86 & 0.035 & $0.0246(0.016)$ & $0.0175(0.0141)$ & 1.45 & 0.114 \\
\hline LEP & $0.0803(0.0847)$ & $0.0653(0.0539)$ & 1.24 & 0.477 & $0.0189(0.0151)$ & $0.0222(0.0321)$ & 1.02 & 0.643 \\
\hline
\end{tabular}

AA and AT + T indicate TRIB2 genotypes. "Ratio" indicates mean expression levels of AA where the mean expression levels of AT + TT were set to be 1. Data for UCP1 are not shown as UCP1 transcripts were not detectable in the adipose tissue samples. SD indicates standard deviation 


\begin{tabular}{|l|c|l|l|l|l|l|l|l|l|}
\hline $\begin{array}{l}\text { Base pair } \\
\text { position in } \\
\text { Chr. } 2\end{array}$ & $\begin{array}{l}\text { LD }\left(r^{2}\right) \\
\text { with } \\
\text { rs } 1057001\end{array}$ & Variant ID & Gene & Con & Ehn & DHS & Mot & $\begin{array}{l}\text { eQTL } \\
\text { TRIB2 }\end{array}$ & $\begin{array}{l}\text { eQTL } \\
\text { MIR3125 }\end{array}$ \\
\hline 12736934 & 1.00 & $\mathrm{rs} 35330522$ & TRIB2, intronic & & & & & & \\
\hline 12737181 & 0.93 & $\mathrm{rs} 13016883$ & TRIB2, intronic & & & & & & \\
\hline 12737375 & 0.87 & $\mathrm{rs} 5829384$ & MIR3125, intronic & & & & & & \\
\hline 12738890 & 0.97 & $\mathrm{r} 35143408$ & TRIB2, intronic & & & & & & \\
\hline 12739061 & 1.00 & $\mathrm{r} 35056165$ & TRIB2, intronic & & & & & & \\
\hline 12741652 & N.D. & $\mathrm{r} 1057001$ & TRIB2, 3'UTR & & & & & & \\
\hline 12742697 & 1.00 & $\mathrm{r} 113137265$ & TRIB2, 3'UTR & & & & & & \\
\hline 12743940 & 0.98 & $\mathrm{r} 6717278$ & TRIB2, downstream & & & & & & \\
\hline 12747576 & 0.98 & $\mathrm{rs} 1974923$ & TRIB2, downstream & & & & & & \\
\hline 12750734 & 0.98 & $\mathrm{rs} 2113818$ & TRIB2, downstream & & & & & & \\
\hline 12752803 & 0.83 & $\mathrm{r} 2059428$ & TRIB2, downstream & & & & & & \\
\hline
\end{tabular}

Fig. 1 Functional annotation of the short nucleotide sequence variants in strong linkage disequilibrium (LD) with rs1057001. Red color indicates SNPs located in an evolutionarily conserved site (Con), in enhancer histone marks in adipocytes (Ehn), in DNase hypersensitive site (DHS), and in protein-binding motif sequences (Mot). Nucleotide sequence variants associated with expression levels of nearby genes (TRIB2 and/or MIR3125) in previous studies are also indicated in red. The functional annotation of the nucleotide sequence variants was performed using Haploreg4.1

adaptation in ancestors of East Asians in the last glacial period [7]. The suppression of Trib2 has been shown to reduce the degradation of CEBPB, a key transcription factor involved in brown adipocyte differentiation in murine models $[8,9]$. This suggests that the AA genotype, which is linked with suppressed expression of TRIB2, is associated with more potent differentiation of thermogenic adipocytes. Transcription levels of $U C P 1$, an important component of the thermogenic machinery of brown and beige/brite adipocytes, were very low in the present adipose tissue samples. UCP1 expression is known to occur at very low levels in non-stimulated white adipose tissues in mice and humans [18, 19]. The present adipose tissue samples, which were obtained from patients who were not subject to cold simulation, did not exhibit high levels of UCP1 expression.

The present study has several potential limitations, which should be addressed in future work; (1) the observed gene expression pattern may be confounded by non-adipocyte cell populations, mainly stromal vascular cells, in the adipose tissues. (2) It is unclear whether the abdominal SAT mirrors the white adipose tissues in the supraclavicular region, which represents the main site of expression of thermogenic genes in human beige/brite adipocytes [19]. (3) The molecular mechanisms underlying the modulation of thermogenic gene expression by TRIB2 remain unknown.

In conclusion, the present study provides evidence for the role of TRIB2 in energy expenditure in adipose tissues. These findings are believed to explain the previously proposed positive natural selection for the TRIB2 cold-adaptive variant during the last glacial period.

\section{Abbreviations}

ACC: Acetyl-CoA carboxylase; ADIPOQ: Adiponectin; ADRB3: Adrenoceptor beta 3; CDNA: Complementary DNA; CEBPB CCAAT: Enhancer binding proteinbeta;

CIDEA: Cell death-inducing DFFA-like effector A; DGAT1: Diacylglycerol

O-acyltransferase 1; DIO2: lodothyronine deiodinase 2; DNA: Deoxyribonucleic acid; FABP4: Fatty acid-binding protein 4; FASN: Fatty acid synthase; GLUT4: Facilitated glucose transporter, member 4; LD: Linkage disequilibrium; LEP: Leptin; PCR: Polymerase chain reaction; PDRM16: PR/SET domain 16; PPARGC1A: PPARG coactivator 1 alpha; RNA: Ribonucleic acid; RT-PCR: Real-time PCR; SAT: Subcutaneous adipose tissues; SCD1: Stearoyl-CoA desaturase 1; SNP: Single-nucleotide polymorphism; SREBP1: Sterol regulatory element binding protein 1; TRIB2: Tribbles pseudokinase 2; UCP1: Uncoupling protein 1; VAT: Visceral adipose tissues

\section{Acknowledgments}

We are grateful to the participants of the present study.

\section{Funding}

This work was partly supported by the MEXT KAKENHI Grant Numbers 26291096 and 26251050.

\section{Availability of data and materials}

The datasets during and/or analyzed during the current study are available from the corresponding author on reasonable request.

\section{Authors' contributions}

KN conceived this study. SI provided the DNA and cDNA samples. KN performed the experiments. KN wrote the manuscript. Both authors read and approved the final manuscript.

\section{Competing interests}

The authors declare that they have no competing interests.

\section{Consent for publication}

Not applicable

\section{Ethics approval and consent to participate}

The design of this study was approved by the Ethical Committee of the Jichi Medical University. All participants provided written informed consent. 
Received: 17 January 2017 Accepted: 13 February 2017

\section{Published online: 17 February 2017}

\section{References}

1. Neel JV. Diabetes mellitus: a "thrifty" genotype rendered detrimental by "progress"? Am J Hum Genet. 1962;14:353-62.

2. Prentice AM, Hennig BJ, Fulford AJ. Evolutionary origins of the obesity epidemic: natural selection of thrifty genes or genetic drift following predation release? Int J Obesity. 2008;32:1607-10.

3. Nishimura T, Motoi M, Egashira Y, Choi D, Aoyagi K, Watanuki K. Seasonal variation of non-shivering thermogenesis (NST) during mild cold exposure. J Physiol Anthropol. 2015;34:11.

4. Sellayah D, Cagampang FR, Cox RD. On the evolutionary origins of obesity: a new hypothesis. Endocrinology. 2014;155:1573-88.

5. Hancock AM, Clark VJ, Qian Y, Di Rienzo A. Population genetic analysis of the uncoupling proteins supports a role for UCP3 in human cold resistance. Mol Biol Evol. 2011;28:601-14.

6. Yoneshiro T, Ogawa T, Okamoto N, Matsushita M, Aita S, Kameya T, et al. Impact of UCP1 and beta3AR gene polymorphisms on age-related changes in brown adipose tissue and adiposity in humans. Int J Obesity. 2013;37: 993-8.

7. Nakayama K, Ogawa A, Miyashita H, Tabara Y, Igase M, Kohara K, et al. Positive natural selection of TRIB2, a novel gene that influences visceral fat accumulation, in East Asia. Hum Genet. 2013;132:201-17.

8. Naiki T, Saijou E, Miyaoka Y, Sekine K, Miyajima A. TRB2, a mouse Tribbles ortholog, suppresses adipocyte differentiation by inhibiting AKT and C/EBPbeta. J Biol Chem. 2007;282:24075-82.

9. Kajimura S, Seale P, Kubota K, Lunsford E, Frangioni JV, Gygi SP, et al. Initiation of myoblast to brown fat switch by a PRDM16-C/EBP-beta transcriptional complex. Nature. 2009;460:1154-8.

10. Yoneshiro T, Saito M. Activation and recruitment of brown adipose tissue as anti-obesity regimens in humans. Ann Med. 2015;47:133-41.

11. Wang W, Seale P. Control of brown and beige fat development. Nat Rev Mol Cell Biol. 2016;17:691-702.

12. Munkhtulga L, Nagashima S, Nakayama K, Utsumi N, Yanagisawa Y, Gotoh T, et al. Regulatory SNP in the RBP4 gene modified the expression in adipocytes and associated with BMI. Obesity. 2010;18:1006-14.

13. Ward LD, Kellis M. HaploReg: a resource for exploring chromatin states, conservation, and regulatory motif alterations within sets of genetically linked variants. Nucleic Acids Res. 2012;40:D930-4.

14. Bostrom P, Wu J, Jedrychowski MP, Korde A, Ye L, Lo JC, et al. A PGC1alpha-dependent myokine that drives brown-fat-like development of white fat and thermogenesis. Nature. 2012;481:463-8.

15. Fisher FM, Kleiner S, Douris N, Fox EC, Mepani RJ, Verdeguer F, et al. FGF21 regulates $\mathrm{PGC}-1$ alpha and browning of white adipose tissues in adaptive thermogenesis. Genes Dev. 2012;26:271-81.

16. Petrovic N, Walden TB, Shabalina IG, Timmons JA, Cannon B, Nedergaard J. Chronic peroxisome proliferator-activated receptor gamma (PPARgamma) activation of epididymally derived white adipocyte cultures reveals a population of thermogenically competent, UCP1-containing adipocytes molecularly distinct from classic brown adipocytes. J Biol Chem. 2010; 285(10):7153-64.

17. Seale P, Kajimura S, Yang W, Chin S, Rohas LM, Uldry M, et al. Transcriptional control of brown fat determination by PRDM16. Cell Metab. 2007;6:38-54.

18. Seale P, Conroe HM, Estall J, Kajimura S, Frontini A, Ishibashi J, et al. Prdm16 determines the thermogenic program of subcutaneous white adipose tissue in mice. J Clin Invest. 2011;121:96-105.

19. Jespersen NZ, Larsen TJ, Peijs L, Daugaard S, Homoe P, Loft A, et al. A classical brown adipose tissue mRNA signature partly overlaps with brite in the supraclavicular region of adult humans. Cell Metab. 2013;17:798-805.

\section{Submit your next manuscript to BioMed Central and we will help you at every step:}

- We accept pre-submission inquiries

- Our selector tool helps you to find the most relevant journal

- We provide round the clock customer support

- Convenient online submission

- Thorough peer review

- Inclusion in PubMed and all major indexing services

- Maximum visibility for your research

Submit your manuscript at www.biomedcentral.com/submit 